\title{
Production and Evaluation of the Physicochemical, Functional and Sensory Properties of Sweetpotato Gari Affected by Soybean mash inclusion
}

\author{
Agbara, Gervse Ikechukwu ${ }^{1 *}$, Masaya Fatima Ajiya ${ }^{2}$, Igwegbe Amin Oderaa ${ }^{1}$, Bade Aminu ${ }^{3}$, Mohammed U. Inna ${ }^{1}$. \\ ${ }^{1 *}$ Department of Food Science and Technology, University of Maiduguri, Nigeria, P.M.B, 1069, Maiduguri. \\ ${ }^{2}$ Department of Nutrition and Dietetics, Ramat Polytechnic Maiduguri, P.M.B. 1070, Maiduguri \\ ${ }^{3}$ Department of Food Science and Technology, Kano State University, Wudil, Nigeria,
}

\begin{abstract}
Parboiled and dehulled soybean mash were added to sweetpotato mash on a replacement basis(0-40\%), thereafter fermented for 72 hours. The sifted fermented mash were toasted to produce sweetpotato-soybeangari, the untreated cassava and sweetpotato gari served as the controls. The different gari types were subjected to physicochemical, functional and sensory evaluation. Untreated sweetpotato and cassava gari had greater titratableacidity(TTA) of $1.33 \%$ and $1.22 \%, \mathrm{pH}, 3.81$ and 4.07 respectively. $\mathrm{pH}$ decreased and TTA increased during the fermentation process, the fermented mashes had the highest TTA and least $\mathrm{pH}$. The moisture(12.30$13.23 \%)$, protein(1.94-9.01\%), fat (0.56-3.09\%), ash(1.40$2.30 \%)$ fibre (1.56-1.90\%) contents were enhanced and carbohydrate $(71.22-83.37 \%)$ decreased progressively with increasing supplementation. Food energy(336.92-356.43kcal) increased with the increase in fat contents of the treated samples. Bulk densities (BD) were higher in the treated and varied from 0.56 to $0.81 \mathrm{~g} / \mathrm{cc}$; swelling indices (SI) and water absorption capacities (WAC) decreased in the treated, varied respectively from 2.23 to $3.84 \mathrm{ml} / \mathrm{g}$ and 1.75 to $1.94 \mathrm{ml} / \mathrm{g} ; 40 \%$ substitution had the least WAC and SI values, highest BD. The treated gari or eba had better appearance, but their taste and texture depreciated with higher inclusion of soybean. It was concluded that at $20 \%$ soybean addition the nutritional value of sweetpotato gari was enhanced without undermining its functional and organoleptic properties.
\end{abstract}

\subsection{INTRODUCTION}

Gari is a free flowing granular lactic acid fermented product obtained from dewatered fermented cassava (Manihotesculenta) mash. It is a staple in many countries of West Africa, its consumption has continued to widen cutting across all social strata and age groups. Gari is a dehydrated product, therefore its storage stability is high and unlike the cassava roots, most well processed gari have reduced level of cyanogenic glycosides far lower than in the cassava roots. ${ }^{[1]}$. Moreover, the convenience in its storage and preparation make gari a food item desired by time-conscious on-themove urban dwellers .Gari is eaten in form of $e b a$ (stiff dough) with soup or stew or soaked in water or liquid milk and consumed along with such food items as roasted peanuts, dry fish, coconut, palm kernels, akara balls (deepfried cowpea paste) etc as a refreshing food drink. Cyanide toxicity from ill processed gari is a concern to gari consumers; quick turnover and sharp practices in an unregulated gari business has further heightened this public health concern. Cassava Gari is a starchy stuff with variable dry matter, about $1-3 \%$ protein, less than $1-2 \%$ fat,7-
$16 \%$ moisture, $1.5-2.5 \%$ ash or fibre contents [2,1,3,4,5], therefore its nourishment comes from food accompaniment with which it is usually consumed.

Sweetpotato (Ipomoea batatas L.), a herbaceous, dicotyledonous dietary root vegetable is a perennial vine with underground edible tuberous root with variable shades of skin colour (cream, yellow, orange, brown , purple). It is thought to originate from pre-Columbian tropical America and now is grown in tropical and warm temperate regions of the world. Sweetpotato is grown in the Southern and Central states of Nigeria where other roots and tubers are extensively grown ${ }^{[6,7]}$. It is commonly eat as fried or boiled, alone or in combination with other food items. Sweetpotato and cassava share many common features, both are tuberous roots that tolerate the same agro-climatic conditions with similar chemical composition, it is a wonder that sweetpotato gari is not known, a crop not known to contain toxic cyanogenic glycosides, instead some varieties are exceptionally loaded with anthocyanin, an antioxidant and beta carotene, a provitamin A. Therefore, this crop is being used as a vehicle for providing school age children with daily requirements of vitamin A in Sub-Saraharan Africa and other regions of the world. Nigeria is among countries with high burden of vitamin A deficiency affecting $29.5 \%$ of the population(eHealthAfrica,2016). Prolonged deprivation of essential amino acids or nitrogen and energy substrates is the root cause of protein-energy malnutrition ${ }^{[8]}$. Nigeria has an unenviable position as having the highest rate of malnutrition in the world with over 300,000 children dying yearly and another 10 million with stunted growth ${ }^{[9]}$. Sweet potato gari alone will not provide the needed protein for growth, maintenance and wellness to consumers mainly those with low purchasing power; on afresh weight basis $100 \mathrm{~g}$ contains: $17.12 \mathrm{~g}$ carbohydrate, $1.6 \mathrm{~g}$ protein, $0.05 \mathrm{~g}$ fat,3.0g dietary fibre, 14,187IU of vitamin A and 8905ug of beta carotene, good amounts of minerals and vitamins ${ }^{[10]}$. Soybean is very important in food processing because of its functionality, high nutritional value $38 \%$ protein, $5 \%$ ash, $30 \%$ carbohydrate, $20 \%$ fat, $7.3 \%$ fibre) and health benefits. ${ }^{[11,12]}$. Although gari from cassava roots is known, a staple for many Nigerians in the humid forest zone, little or nothing is known of sweetpotato gari; its production will reduce its high postharvest loses, lessen the pressure on cassava gari, further addition of soybean will enhance its 
nutrient density. Therefore the thrust of this study was to produce gari from sweetpotato roots, supplement the same with different levels of soybean mash and evaluate the physicochemical and sensory properties of the sweetpotatosoybean gari.

\subsection{MATERIALS AND METHODS}

\subsection{Collection of raw materials}

Fresh cassava $(5 \mathrm{~kg}), \quad$ sweet potatoes(yellowfleshed, $15 \mathrm{~kg}$ ), soybean seeds(cream coloured,10 kg) were purchased at a local market (Gamboru Vegetable, Maiduguri) and transferred to the Food Processing Lab. of Food Science and Technology, University of Maiduguri.

\subsection{Preparation of the sweet potato-soybean gari}

The tubers were washed, peeled with stainless knife, sliced for easy grating on hammer mill, sweetpotato were sliced directly into hot water, $(<95 \mathrm{c})$ and left for two to three minutes to inhibit enzymatic browning before grating. Soybean seeds were sorted, washed, and given ten minutes parboiling for easy dehulling, the dehulled seeds were ground into smooth mash.

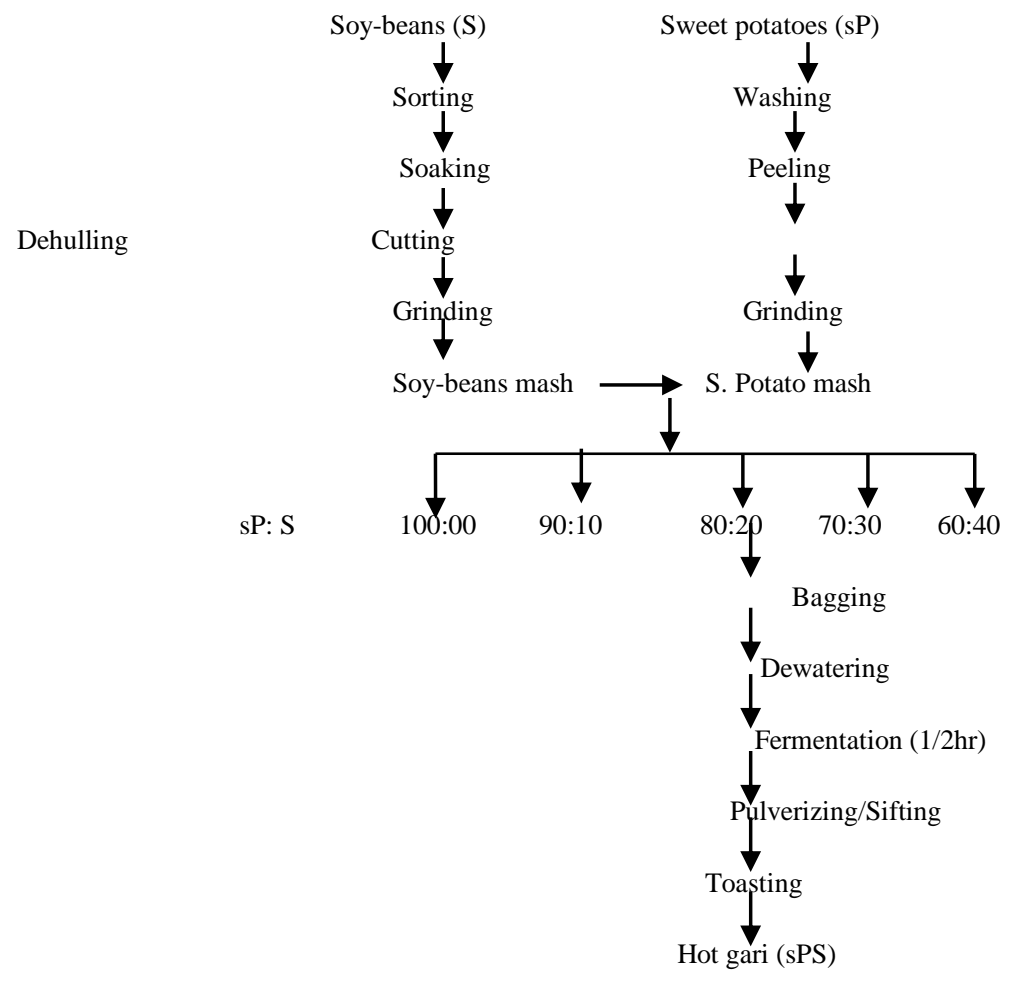

Fig 1. Flow diagram for the production of Sweetpotato-Soybean gari and the control (cassava gari)

\subsection{Physicochemical Analysis of Gari}

The bulk density (BD) of the various gari were determined by the method of ${ }^{[13]}$. Water absorption capacity (WAC) was determined using the method of [14] involving $1 \mathrm{~g}$ sample in $10 \mathrm{ml}$ of distilled water, left standing for $30 \mathrm{mins}$ then centrifuging at $3000 \mathrm{rpm}$ for $30 \mathrm{~min}$. Swelling index was determined using the method described by ${ }^{[2]}$; suspending $10 \mathrm{~g}$ of the sample in $50 \mathrm{ml}$ of distilled water, stirred and left to stand for $1 \mathrm{~h}$, the difference between final and the initial volumes pet unit sample weight was taken as swelling index. The $\mathrm{pH}$ of the mash was determined using
The sweet potato $(\mathrm{sP})$ and soybean $(\mathrm{S})$ mashes were mixed in the following ratios: sPS100:00, sPs90:10,sPs80:20, sPs70:30, sPs60:40, while C100 :00(cassava mash)served as the control along with sP100.00. Each of the formulation was thoroughly mixed in Kenwood mixer and placed into a cotton bag and dewatered by pressing the bagged mash, after which they were allowed to ferment for $72 \mathrm{hrs}$ under ambient condition. The fermented mashes were individually pulverized, sifted using a local cane sieve, thereafter toasted on a shallow iron pan over a low flame heat source accompanied with continuous stirring of the mash until the moisture content was sufficiently reduced, the starch sterilized

The free flowing hot gari was placed on a shallow container to cool, it was sieved with a colander to obtain gari of uniform particle sizes and packaged prior to analysis. The flow diagram for the preparation of the control and soybean supplemented sweet potato is displayed in Fig.1. solution obtained from dewatering process, that of gari was obtained by placing $10 \mathrm{~g}$ of gari in a flask containing $50 \mathrm{ml}$ of distilled water, mixed and left standing for $30 \mathrm{~min}$ and later filtered, the $\mathrm{pH}$ of the filtrates were taken using a $\mathrm{pH}$ meter (Jenway 3330, UK). Ten mililitre $(10 \mathrm{ml})$ of each filtrate was used to determine the titratable acidity (TTA) according to the method of AOAC ${ }^{[15]}$, the results were expressed on the basis of lactic acid using the formula:

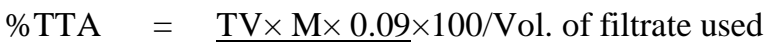


where $\mathrm{M}=$ molarity of $\mathrm{NaOH}, \mathrm{TV}=$ titre value, $0.09=$ lactic acid milliequivalent.

\subsection{Proximate composition}

The proximate composition of sweetpotato-soybean (sPS) gari samples and the controls were determined according to the procedures of AOAC ${ }^{[15]}$, method No. 950.46, 920.153, 991.36, 928.08 and 993.21 for moisture, ash, fat, protein and fibre respectively. Results were expressed in percent $(\%)$ Carbohydrate contents(CHO) of the gari was obtained by difference. $\% \mathrm{CHO}=100-(\%$ Protein $+\%$ fat $+\%$ ash $+\%$ fibre $+\%$ moisture).Food energy (E) was obtained by multiplying the gross nutrients(protein, fat and carbohydrate) contents with Awater conversion factors and the sum total expressed in $\mathrm{kcal} / 100 \mathrm{~g}$.

\subsection{SENSORY EVALUATION}

Raw gari and the controls were assessed using students and staff (15) drawn from the department (Food Science and Technology).A 9-point hedonic scale (where 1 represents extremely disliked, 9 extremely liked), was used evaluate the following attributes: colour, taste, aroma, texture (hand feel)and the overall acceptability, the same panel also evaluated eba (stiffed gari dough) obtained from raw gari on the same scale and the same attributes. Coded samples were randomly presented to the panelists, water was provided for mouth gargling before proceeding to the next sample.

\subsection{Statistical analysis}

The mean and standard deviation were calculated of triplicate determinations. Results were reported as mean \pm SD.

\subsection{RESULTS AND DISCUSSION}

Higher TTA and lower $\mathrm{pH}$ values were generally observed, more in the untreated samples; an inverse relationship existed between these two parameters. There were progressive decrease in the titratableacidity (TTA) in the unfermented(0.164-0.105\%), fermented $(0.52 \%-0.23 \%)$ mashes and the sweetpotato gari samples (3.70\%-3.54\%) which linearly decreased with increased addition soybean mash to sweet potato (Table 2). The outcome was decreased carbohydrate availability i.e. decreased level of fermentable substrates, this might be responsible for the observed decrease in TTA and increase in $\mathrm{pH}$ values. As for the treated samples, the highest $\mathrm{p}^{\mathrm{H}}(6.38-6.69)$ values were observed in the unfermented mashes and the least (3.41-3.59) in the fermented mashes. The $\mathrm{pH}$ of the treated gari varied from 3.70 to 4.96 , that of $100 \%$ cassava and $100 \%$ sweetpotato gari were 4.07 and 3.81, their TTA values $1.22 \%$ and $1.33 \%$ respectively. The fermented mashes were the most acidic. This indicates that toasting leads to loss of weak acids formed during fermentation of the mash. Reference ${ }^{[16]}$ studied the effect of fermentation time on sweetpotato gari, a $\mathrm{pH}$ range of 6.41 day zero that decreased to5.69 the $4^{\text {th }}$ day and TTA to $26 \mathrm{mg} / \mathrm{g}(2.6 \%)$. ${ }^{[17]}$ worked on cassava-sweetpotato gari and reported a TTA of $1.60 \%$ and $1.70 \%$; a pH of 4.75 and 4.90 respectively for $100 \%$ cassava and $100 \%$ sweetpotato gari used as the control. These reported findings were comparable to the observations obtained in this study. Reference ${ }^{[4]}$ studied the effect of preferment liquor on properties of cassava gari, the fresh mash had a $\mathrm{p}^{\mathrm{H}}$ of 5.6 which dropped to 4.6 $72 \mathrm{~h}$ later and the gari had a $\mathrm{pH}$ range of 4.56-4.10 and TTA of $0.040-0.079 \%$ was comparatively negligible. In this study, the higher the inclusion of soybean the higher the $\mathrm{pH}$ and lower the TTA of both the mash and gari. Consumers prefer acidic gari and used high acidity(sourness) as indicator of high quality and storage stability. It is to be noted that total TTA includes naturally available organic acids such as citrates, lactates, acetates e.t.c or developed organic acids in the course of fermentation by lactic acid bacteria. Higher amounts of fermentable free sugars in these roots more in sweetpotato ${ }^{[18]}$ than in cassava might be responsible for higher TTA in the untreated samples contrary to findings of ${ }^{[19]}$ that reported a TTA range of $0.54-0.84$ for gari from three cassava cultivars; but comparable to findings of ${ }^{[1]}$ that had earlier reported a TTA range of $0.85 \%-0.99 \%$ and $\mathrm{p}^{\mathrm{H}}, 3.4$ -4.0 for gari from selected cultivars and ${ }^{[16]}$ who worked on effect of fermentation time on sweetpotato gari.

Table 1: $\mathrm{P}^{\mathrm{H}}$ and Tritratable Acidity (TTA)\% of the Sweet potato-Soybean mash and Gari

\begin{tabular}{|c|c|c|c|c|c|c|c|c|}
\hline \multirow[t]{2}{*}{ Sample Code } & \multicolumn{3}{|c|}{ Unfermented mash } & & \multicolumn{2}{|c|}{ Fermented mash } & \multicolumn{2}{|c|}{ Gari } \\
\hline & TTA & & $\mathrm{PH}$ & & TTA( & & TTA & $\mathrm{PH}$ \\
\hline C100:0 & $0.373 \pm 0.007$ & $6.28 \pm 0.03$ & $0.89 \pm 0.01$ & $3.22 \pm 0.02$ & $1.22 \pm 0.03$ & $4.07 \pm 0.02$ & & \\
\hline sP100:0 & $0.188 \pm 0.005$ & $6.23 \pm 0.03$ & $0.63 \pm 0.03$ & $3.21 \pm 0.04$ & $4 \quad 1.33 \pm 0.03$ & $3.81 \pm 0.07$ & & \\
\hline sPS90:10 & $0.164 \pm 0.009$ & $6.38 \pm 0.07$ & $0.52 \pm 0.02$ & $3.41 \pm 0.06$ & $6 \quad 0.56 \pm 0.06$ & $3.70 \pm 0.02$ & & \\
\hline sPS80:20 & $0.135 \pm 0.005$ & $6.50 \pm 0.06$ & $0.48 \pm 0.02$ & $3.40 \pm 0.02$ & $2 \quad 0.58 \pm 0.01$ & $3.73 \pm 0.03$ & & \\
\hline sPS70:30 & $0.123 \pm 0.004$ & $6.61 \pm 0.05$ & $0.28 \pm 0.02$ & $3.49 \pm 0.04$ & $4 \quad 0.54 \pm 0.02$ & $3.60 \pm 0.02$ & & \\
\hline sPS60:40 & $0.105 \pm 0.006$ & $6.69 \pm 0.03$ & $0.23 \pm 0.03$ & $3.59 \pm 0.02$ & $2 \quad 0.50 \pm 0.02$ & $3.54 \pm 0.02$ & & \\
\hline
\end{tabular}

The functional properties as shown in Table 2 indicates that the untreated cassava and sweet potato gari had the highest water absorption capacities (WAC) $1.94 \mathrm{ml} / \mathrm{g}$ and $1.89 \mathrm{ml} / \mathrm{g}$ ) and swelling indices (SI) $3.84 \mathrm{ml} / \mathrm{g}$ and 3.80 $\mathrm{ml} / \mathrm{g}$ ) and the least bulk densities (BD) $0.56 \mathrm{~g} / \mathrm{cc}$ and 0.59 $\mathrm{g} / \mathrm{cc}$ ) respectively, these values dropped in the treated samples, the gari with highest substitution $(40 \%$ soybean mash)having the least values of SI and WAC but highest $\mathrm{BD}$. The BD indicates density of matter in a unit volume. Reduced starch and increased fat contents as a result of soybean addition might be responsible for decreased SI and $\mathrm{WAC}$ in the treated gari. High WAC,SI, and BD are 
quality parameters of a good gari. The ability of starch granules to imbibe water and swell is more a function of starch than protein content and is affected by material particle size [20] and moisture. Hydration capacity is detected by the presence of starch and protein especially the net balance between hydrophilic and hydrophobic amino acids, protein size and its configuration [21]. Lower bulk density on the other is needed for easier packaging, storage and distribution ${ }^{[20]}$. For the treated gari, BD varied from $0.62-0.81 \mathrm{~g} / \mathrm{ml}$, SI 2.23-3.64 $\mathrm{ml} / \mathrm{g}$ and WAC 1.75-1.83 $\mathrm{ml} / \mathrm{g}$.
Reference ${ }^{[5]}$ reported $\mathrm{BD}, \mathrm{WAC}$ and SI of cassavacocoyam gari as $0.54-0.82 \mathrm{~g} / \mathrm{cc}, 100-150 \%$ and $174-220 \%$ respectively, the control cassava gari had the highest WAC and SI but the least BD; reference ${ }^{[4]}$ reported SI, BD and WAC of $0.544-0.604 \mathrm{~g} / \mathrm{cc}, 21.61 \mathrm{ml}-26.19 \mathrm{ml}$ and 1.15 $1.44 \mathrm{ml} / \mathrm{g}$ respectively. These reported values are comparable to values shown in Table 3 which clearly indicates negative effect of supplementation on WAC and SI. Functional properties are governed by processing methods, particle size distribution, quality and quantity of nutrients in addition to presence of food additives.

Table 2: Functional properties of sweet potato-Soybean (sPS) Gari and the controls.

\begin{tabular}{lcrl}
\hline Sample code & $\mathrm{BD}(\mathrm{g} / \mathrm{cc})$ & $\mathrm{SI}(\mathrm{ml} / \mathrm{g})$ & $\mathrm{WAC}(\mathrm{ml} / \mathrm{g})$ \\
\hline C100:0 & $0.56_{ \pm 0.02}$ & $3.84_{ \pm 0.05}$ & $1.94_{ \pm 0.05}$ \\
sP100:0 & $0.59_{ \pm 0.02}$ & $3.80_{ \pm 0.02}$ & $1.89_{ \pm 0.04}$ \\
sPS90:10 & $0.62_{ \pm 0.03}$ & $3.64_{ \pm 0.02}$ & $1.83_{ \pm 0.03}$ \\
sPS80:20 & $0.67_{ \pm 0.02}$ & $2.89_{ \pm 0.03}$ & $1.81_{ \pm 0.02}$ \\
sPS70:30 & $0.73_{ \pm 0.03}$ & $2.51_{ \pm 0.10}$ & $1.77_{ \pm 0.05}$ \\
sPS60:40 & $0.81_{ \pm 0.04}$ & $2.23_{ \pm 0.03}$ & $1.75_{ \pm 0.03}$ \\
\hline
\end{tabular}

$\mathrm{BD}=$ bulk density; $\mathrm{SI}=$ swelling index; WAC=water absorption capacity; means \pm SD of triplicate determinations

Cassava gari (C100:00) had the least moisture, protein, fat, fiber but the highest carbohydrate contents while sweetpotato gari (SP100:0) had greater values of these nutrients than $\mathrm{C} 100: 0$, but there were progressive increase in the values of fat, protein, ash, fiber and a decrease in carbohydrate content with progressive substitution of sweet potato with soybean(Table 3) .Moisture, protein, fat, ash, fiber and carbohydrate contents of the treated samples varied from $12.30-13.23 \%, 2.49-9.01 \%, 1.68-3.83 \%$, $1.87-3.38 \%, 1.76-2.06 \%$ and $71.40-79.01 \%$ respectively. All the nutrients were enhanced with soybean addition since soybean is a rich source of ash $(5.5 \%)$, protein $(42.8 \%)$, fat $(18.8 \%)$ and dry matter $(92.0 \%)^{[22]}$. Soybeans is abundantly used to fortify foods both for functional and nutritive reasons especially starchy crops such as sweetpotato. Reference ${ }^{[23]}$ reported nine varieties of orange fleshed sweetpotato as containing: $70.95 \%$ 72.965 moisture, $1.90-5.83 \%$ protein, $0.17-0.63 \%$ fat, 0.30 $0.54 \%$ crude fibre, $0.17-1.31 \%$ crude ash and $21-25 \%$ carbohydrate, fresh weight basis. Reference ${ }^{[24]}$ reported similar enhancement of nutrient density of wheat flour with soybean supplementation. Reference [5] studied garianalogue (cassava-cocoyam gari) and reported the following values: protein $1.57-4.43 \%$, ash $1.89-2.19 \%$, moisture $7.28-7.78 \%$ and fiber $1.53-2.19 \%$.

Gari samples without supplementation studied by ${ }^{[25]}$ and ${ }^{[17]}$ had lower mean proximate values that are similar to untreated cassava or sweetpotato gari used as the control in this study. ${ }^{[26]}$ reported the proximate values of cassavabambara nut gari as follows: moisture $11.38-12.60 \%$ protein $0.98-4.68 \%$, fat $1.10-2.60 \%$, ash $1.82-2.80 \%$, crude fibre $2.26-2.42 \%$ and carbohydrate $78.20-83.50 \%$.These findings in addition to that of ${ }^{[16]}$ for sweetpotato gari (protein $4.6 \%$, ash $2.66 \%$, fat $1.02 \%$ ) strengthen the findings observed in this study. Inclusion of legumes such as soybeans in the formulation of new or modification of existing food products indeed has beneficial effects as observed in the enhanced nutrient density of the samples. However, variation in the reported values might be attributed to differences in cultivated varieties, processing methods, agronomic practices, and soil compositions ${ }^{[27]}$.

Table 3: Proximate Composition(\%) of Sweet potato-Soybean(sPS) Gari and the Controls.

\begin{tabular}{lllllccc}
\hline $\begin{array}{l}\text { Sample } \\
\text { code }\end{array}$ & Moisture & Protein & Fat & Ash & Fibre & CHO & $\begin{array}{c}\text { Energy } \\
(\mathrm{kcal} / 100)\end{array}$ \\
\hline C100:0 & $10.82 \pm 0.18$ & $2.29 \pm 0.09$ & $0.56 \pm 0.04$ & $1.40 \pm 0.04$ & $1.56 \pm 0.13$ & $83.37 \pm 0.12$ & 347.68 \\
sP100:0 & $13.23 \pm 0.05$ & $1.94 \pm 0.12$ & $0.70 \pm 0.02$ & $1.74 \pm 0.05$ & $1.69 \pm 0.27$ & $81.70 \pm 0.16$ & \\
sPS90:10 & $13.19 \pm 0.04$ & $2.49 \pm 0.03$ & $1.68 \pm 0.04$ & $1.87 \pm 0.03$ & $1.76 \pm 0.05$ & $79.01 \pm 0.20$ & 336.92 \\
sPS80:20 & $12.50 \pm 0.05$ & $4.40 \pm 0.11$ & $1.91 \pm 0.08$ & $1.95 \pm 0.05$ & $1.79 \pm 0.06$ & $77.75 \pm 0.17$ & 341.12 \\
sPS70:30 & $12.34 \pm 0.06$ & $8.60 \pm 0.27$ & $3.09 \pm 0.08$ & $2.30 \pm 0.02$ & $1.90 \pm 0.01$ & $71.77 \pm 0.10$ & 344.59 \\
sPS60:40 & $12.30 \pm 0.04$ & $9.01 \pm 0.18$ & $3.83 \pm 0.07$ & $3.38 \pm 0.07$ & $2.06 \pm 0.06$ & $71.40 \pm 0.10$ & 349.29 \\
\end{tabular}

Results are means $\pm \mathrm{SD}$ of three replicates; $\mathrm{C}=$ cassava; $\mathrm{SP}=$ sweetpotato; $\mathrm{S}=$ soybean $\mathrm{CHO}=$ carbohydrate

Untreated cassava and sweetpotato gari had the least score in colour respectively 6.73 and 6.40 , browning reaction is more pronounced in sweetpotato than in cassava roots; the texture of cassava and sweetpotato gari were the best(graininess) (8.0-8.2) which reduced with soybean addition; the taste(sourness) of untreated cassava and sweet potato gari and $10 \%$ soyabean substituted gari were the best which decreased with soybean addition; aroma of all the gari were generally liked and the overall acceptability score of each gari was greater than 7.4. Gari with $40 \%$ substitution had the poorest taste (6.4), texture(6.7) and least overall acceptability score (7.4), however none was rejected (Table 4 ). 
Table 4:Sensory attributes of raw sweetpotato-soybean gari and the controls.

\begin{tabular}{lllllc}
\hline Sample code & Colour & Taste & Aroma & Texture & Acceptability \\
\hline C100:0 & $6.73 \pm 0.31$ & $8.06 \pm 0.15$ & $7.6 \pm 0.20$ & $8.43 \pm 0.15$ & $8.2 \pm 17$ \\
sP100:0 & $6.40 \pm 0.18$ & $7.6 \pm 0.23$ & $7.97 \pm 0.15$ & $7.80 \pm 0.20$ & $7.06 \pm 25$ \\
sPS90:10 & $7.40 \pm 0.20$ & $7.77 \pm 0.15$ & $8.40 \pm 0.22$ & $7.63 \pm 0.15$ & $7.73 \pm 0.31$ \\
sPS80:20 & $7.80 \pm 0.10$ & $7.4 \pm 0.20$ & $8.13 \pm 0.15$ & $7.00 \pm 0.13$ & $7.17 \pm 0.24$ \\
sPS70:30 & $8.03 \pm 0.29$ & $6.60 \pm 0.20$ & $8.2 \pm 0.10$ & $6.70 \pm 0.10$ & $7.09 \pm 0.21$ \\
sPS60:40 & $8.40 \pm 0.17$ & $6.50 \pm 0.10$ & $8.3 \pm 0.20$ & $6.38 \pm 0.18$ & $6.80 \pm 0.20$ \\
\hline
\end{tabular}

The sensory attributes of eba (stiff paste of gari with hot water) as presented in Table 5 did not depart greatly from the pattern observed for raw gari. The treated eba had better colour (7.30-8.00) than the untreated cassava(6.90) and sweetpotato (6.76) eba but the untreated and $10 \%$ substituted sweetpotato eba had better texture (cohesiveness) greater than 8.00 and the aroma of the eba were all well appreciated (7.73-8.3). All the eba were generally accepted, the acceptance scores were higher with the untreated and reduced linearly with increased soybean addition.

Table 5: Sensory attributes of sweet potato-Soybean $e b a$ (stiff gari dough) and the controls

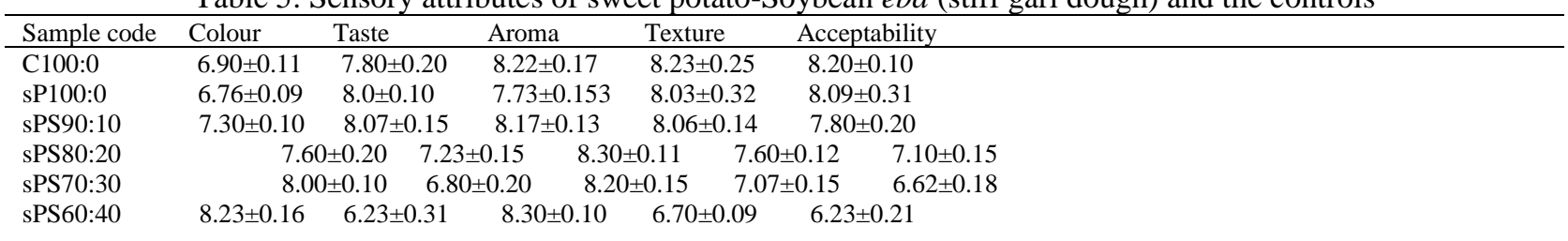

\section{CONCLUSION}

Nutrient density of the treated gari were enhanced with soybean supplementation highest at the highest level of substitution but carbohydrate contents decreased which in turn reduced the swelling indices and water absorption capacities of the treated gari that decreased progressively with increased soybean addition. The sensory attributes were affected, treated sweet potato gari/eba had the best colour but the poorest texture and taste, however all the gari were acceptable. Finally, sweetpotato gari at the level of $20 \%$ substitution with soybean competed favourably with untreated cassava or sweet potato gari in all the parameters that determine good gari and also with better nutritional value.

\section{REFERENCES}

[1] Achinewhu, S.C., Baber, L.I., Jeoma, I.O. (1998), Physicochemical Properties and Garifcation (Gari Yield) of Selected Cassava Cultivars in Rivers State Nigeria. Plant Food Human Nutr.,52:133doi:10.1023/A:1008029101710.

[2] Ukpabi, U.J. and Ndimele, K.O.(1990).Evaluation of Gari in Imo State Nigeria. Nigeria Food Journal 8:105-110.

[3] Ernsto, M., Cardosso, A.P.,J., Cliff and J.H., Bradury. (2000). Cyanogenic Cassava Flour and Roots and Urinary Thiocyanate Concentration in Mozambique. Journal Food Composition Anal.,131:1-12.

[4] Owuamanam, C.I., Ogueke, C.C., Achinewhu, S.C. and Barimalaa, I.S. (2011). Quality Characteristics of as Affected by Preferment, Temperature and Duration of Fermentation.American Journal of Technology.6:374-384

[5] Bamidele, O.P., Ogundele. F.G., Ojubanire, B.A., Fasogbo, M.B. and Bello, O.W. (2014). Nutritional Evaluation Analoque Produced From Cassava and Cocoyam Tubers. Food Sci Nutr,2(6):706-711

[6] Eneji, E., Agbola, A.A., Ubi, B.E.(1997). Effect of Farnyard Manure and NPK Fertilizer on Growth and Yield of Intercropped Maize (Zea mays) and Sweetpotato (Ipomoea batatas) in Southern Nigeria. Revista Agrioltura Subtropicale (Italy),91(1):63-75.

[7] Tewe, O.O., Abu, O.A., Ojenyi, E.F., Nwokocha, N.H.(2001).Sweet Potato Production and Marketing in Nigeria. In: Akoroda, M.O. and J.M., Negev Ed. Root Crops in the Twenty First Century; Proceedings of the7th Triennial Symposium of the International Society for Tropical Crops, African Branch,Cotonou,Benin,October,11-17,1998

[8] Dugler, H., Arik, M., Sekeroglu, M.K., Terakeiglu, N.T., and Cesur, Y. (2002). Proinflamminatory Cytokines in Turkish Children with Protein Energy Malnutrition, Malnutrition Mediators Inflamm.,11,363-365.

[9] eHealth Africa(2016).A Realistic Answer for Nigerian Nutrition Crises. Available:

http//:www.ehealthafrica.org/latest/2016/4.....Accessed on June $26^{\text {th }}, 2016$.

[10] USDA (2009). National Nutrient Data Base for Standard Reference, Release 28. Agricultural Research Service of United States Department of Agriculture. Available: http://www.nal.nasda.gov/fnic/foodcomposition/search/

[11] Ren, H., Hayashi, T.(2006). Antimutagenic and Antioxidative Activities Found in Chinese Traditional Soybean Fermented Products Furu. Food Chemistry V.95, 71-76, http://dx.doi.org/10.1016/j.foodchem.2004.12.019.

[12] Acuna, S.P.C., Gonzale, J.H.G. and Torres, I.D.A.(2012). Physicochemical Characteristics and Functional Properties of Vitabosa (Mucuna deeringiana) and Soybean(Glycin max). Food Science and Technol. Vol. 32

No.1,http://dx.doi.org/10.1590/S0101-20612012005000007.

[13] Okaka, O.C. and Potter, N.N.(1977).Functional and Storage Properties of Cowpea Powder-Wheat Flour Blends in Bread making. Journal of Food Sci. 42(3):828-833.

[14] Sosulki, F.W., Garatt, M.O., Slinkard, A.E.(1976) Functional Properties of Ten Legume Flours.Int. J. Food Sci Technol.66-69.

[15] AOAC(2000) Official Methods of Analysis Vol.2,17 ${ }^{\text {th }}$ Ed. Official Methods923.03,923.05,962.09 and 979.09. Gathersburg, MD Publishers Washington, DC. 
[16] Koubala, B.B., Kansci, G., Enore, L.B.E., and Esame, M.Z. (2014). Effect of Fermentation Time on the Physicochemical and Sensorial Properties of Gari from Sweetpotato (Ipomoea batatas). British Journal Applied Science and Technology.4(24):3430-3444.

[17] Karim, O.R., Adebanke, B.M., Akintayo, O.A. and Awoyale, W.(2006).Physicochemical and Sensory Properties of Cassava-sweetpotato gari. Ukrainian Journal of Food Sci.,4(2):276-289.

[18] Hammed, M.G.E., Hussein, M.F., Refai, F.Y. and ELsamahy, S.K.(1973).Preparation and chemical Composition of Sweetpotato Flour. Cereal Chem., Vol. 20 Issu 2.

[19] Komolafe, E.A. and Arawande, J.O. (2010). Evaluation of Quality and Quantity of Gari Produced From Three Cultivars of Cassava. Journal of Research in National Development, Vol 8 Issue 1.

[20] Karuna D. Kulkami, Noel Govinden and Dilip Kulkami.(1996). Potato Flour in Mauritian Traditional Foods. Food and Nutrition Bulletin, Vol 13, Issiu 2. Available: http://archive.unu.edu/unupress/unupress.htm.

[21] Singh, U. (2001).Functional Properties of Grain Legumes. Journal Food Sci.Technol.,38:191-199.

[22] Banaszkiewicz, T. (2011).Nutritional Value of Soybean Meal, Soybean and Nutrition. Henry El-Shemmy (Ed.). Intech, Available: http://www.intech.com/books soy-andnutrition/nutritional.....

[23] Alam, M.K., Runi Z.H. and S.N., Islam.(2016). Comparason of the Proximate Composition, Total Carotenoid and Total Polyphenols Contents of nine Orange-fleshy Sweetpotato Cultivars Grown in Bangladesh. Foods 53(3):64,doi:10.3390/foods5030064.

[24] Aiyelegun, T., Owolarafe, O., Ogunsina, B., Taiwo, S. (2017).Inconsistency in the Physical Properties of Gari Produced in Southern Nigeria.: A Proposal for Appropriate Technology. Journal of Process Engineering, doi: 10.111/jfpe. 12526

[25] Bankole,T.O.,Tanimola,O.A.,Odunukan,R.O.,Samuel,D.O.(2 013).Assessmentof Functional, Properties Proximate Composition Sensory Evaluation and Rheological value of Gari Fortified with Bambara Groundnut Flour(Voandzeia subterranean Thouars). Academic Journal of Interdisplinary Studies, Vol.2, Issue10.

[26] Madubuike, P.C., Onyema, C.T., Odinma, S.C. and Sokwaibe, C.E. (2014). Evaluation of Mineral Elements ,Cyanide and Proximate Composition of Cassava(Manihotesculenta Crantz) from Egboyi State Nigeria .IOSR J of Env: Sci Toxicology and Food Techology 8(8) Ver 11,41-43 